\title{
QUANTITATIVE ELECTROENCEPHALOGRAPHY (qEEG) TO DISCRIMINATE PRIMARY DEGENERATIVE DEMENTIA FROM MAJOR DEPRESSIVE DISORDER (DEPRESSION)
}

\author{
Andréa Deslandes', Heloisa Veiga ${ }^{1}$, Mauricio Cagy'2, \\ Adriana Fiszman ${ }^{3}$, Roberto Piedade ${ }^{4}$, Pedro Ribeiro ${ }^{5}$
}

\begin{abstract}
Electroencephalography (EEG) can be a valuable technique to assess electrophysiological changes related to dementia. In patients suspected of having dementia, the EEG is often quite informative. The sensitivity of the EEG to detect correlates of psychiatric disorders has been enhanced by means of quantitative methods of analysis (quantitative EEG). Quantitative features are extracted from, at least, 2 minutes of artifact-free, eyes closed, resting EEG, log-transformed to obtain Gaussianity, age-regressed, and Z-transformed relative to population norms (Neurometrics database). Using a subset of quantitative EEG (qEEG) features, forward stepwise discriminant analyses are used to construct classifier functions. Along this vein, the main objective of this experiment is to distinguish profiles of $\mathrm{qEEG}$, which differentiate depressive from demented patients $(n=125)$. The results showed that demented patients present deviations above the control group in variables associated to slow rhythms: Normed Monopolar Relative Power Theta for $\mathrm{Cz}$ and Normed Bipolar Relative Power Theta for Head. On the other hand, the deviation below the control group occurs with the variable associated to alpha rhythm: Normed Monopolar Relative Power Alpha for P3, in dementia. Using this method, the present investigation demonstrated high discriminant accuracy in separating Primary Degenerative Dementia from Major Depressive Disorder (Depression).
\end{abstract}

KEY WORDS: qEEG, neurometrics, Alzheimer's disease, depression.

\section{Eletroencefalografia quantitativa (EEGq) na discriminação entre demência degenerativa primária e transtorno depressivo maior (depressão)}

\begin{abstract}
RESUMO - A Eletroencefalografia (EEG) pode ser utilizada como uma técnica valiosa na avaliação de mudanças eletrofisiológicas relacionadas à demência. Em pacientes com suspeita de demência, o EEG é em geral bastante informativo. A sensibilidade do EEG em detectar correlatos de desordens psiquiátricas pode ser incrementada através de métodos de análise quantitativa (EEG quantitativo). Padrões quantitativos são extraídos de pelo menos 2 minutos de dados livres de artefatos, em que os sujeitos estão com olhos fechados e em estado de repouso. São aplicados métodos quantitativos, tais como: transformação logarítmica para obtenção de uma distribuição Gaussiana, regressão por faixa etária e o escore Z relativo a normas populacionais preestabelecidas (Neurometrics). Utilizando uma amostra de padrões de EEG quantitativo $(\mathrm{EEGq})$, será implementada uma análise discriminante (forward stepwise) a fim de estabelecer funções classificatórias. Neste contexto, o objetivo principal deste estudo é distinguir perfis de EEGq que diferenciem pacientes com depressão de pacientes com demência $(n=125)$. Os resultados demonstraram que pacientes acometidos por demência apresentam desvios acima do grupo controle em variáveis associadas a ritmos lentos: Potência Monopolar Relativa Normalizada em Teta para Cz e Potência Bipolar Relativa Normalizada em Teta para Cabeça. Por outro lado, desvios abaixo do grupo controle ocorrem em variáveis associadas ao ritmo alfa: Potência Monopolar Relativa Normalizada em Alfa para P3. Através deste método, a presente investigação demonstrou uma alta acurácia em discriminar pacientes com Demência Degenerativa Primária de pacientes com Transtorno Depressivo Maior.
\end{abstract}

PALAVRAS-CHAVE: EEGq, neurometrics, doença de Alzheimer, depressão.

\footnotetext{
${ }^{1}$ Mestranda em Saúde Mental, Instituto de Psiquiatria (IPUB), Setor de Neuroimagem Funcional, Universidade Federal do Rio de Janeiro Rio de Janeiro RJ, Brasil (UFRJ); ${ }^{2}$ Doutorando em Engenharia Biomédica, COPPE, (UFRJ); ${ }^{3}$ Doutoranda em Psiquiatria, (IPUB), Setor de Neuroimagem Funcional, (UFRJ); 'PProfessor Adjunto III Doutor, (IPUB), Setor de Neuroimagem Funcional, (UFRJ); ${ }^{5}$ Professor Adjunto II PhD, Escola de Educação Física e Desportos (IPUB), Setor de Neuroimagem Funcional, (UFRJ); Professor Pesquisador, Universidade Castelo Branco (PROCIHM).
}

Received 28 April 2003, received in final form 5 August 2003. Accepted 17 September 2003. 
One of the major challenges in clinical psychiatry is having the ability to differentiate dementia from depression in elderly individuals. This difficulty is mainly associated with a constellation of symptoms shared by both pathologies. Several domains are influenced in both cases, such as: shortterm memory, abstract thinking, ability to make decisions, disturbances of higher cortical function, and mood instability. In special, diagnostic accuracy becomes worse when depression is combined with cognitive detriment. Patterns of depression with cognitive impairment potentially damage patients' ability to store and retrieve information up to a minimal standard. Thus, cortical dementia, as well as pseudodementia (due to depression), will yield a significant damage on the patients' decision-making and information processing abilities.

Electroencephalography (EEG) is unquestionably a precious tool used to assess electrophysiological changes associated with dementia'. As pointed out by Duffy et al. ${ }^{2}$ in patients suspected of having dementia, the EEG is often quite informative. The severity of EEG abnormalities in Alzheimer Disease (AD), the most common cortical dementia, varies according to the degree of cognitive impairment. Lightly abnormal EEG in the early stages of dementia has been indicative of a progressive degenerative trend ${ }^{3}$. During the evolution, the findings include mainly an increase in diffuse slow activity and a reduction in alpha and beta activity ${ }^{4-8}$. Duffy et al. ${ }^{9}$ and Prichep et al. ${ }^{10}$ found diffuse increases in power in the low-frequency band among demented patients, while Coben et al. ${ }^{11}$ reported a decrease in the total power in beta band in subjects with dementia. Brenner et al. ${ }^{12}$ found similar patterns, with a corresponding increased theta-beta ratio between patients with dementia and normal controls. Leuchter et al. ${ }^{13}$ examined the data only from demented patients with mild cognitive impairment and observed that $63 \%$ of these subjects had spectral beta-theta ratio values below the lowest value for the control subjects. The spectral ratio from the left temporal region was much lower among demented subjects. On the other hand, studies of quantitative EEG (qEEG) changes in depressed patients are scarce and have yielded contradictory findings. Brenner et al. ${ }^{6}$ found decreased beta and delta relative power in depressed patients as compared to normal controls. Luthringer et al. ${ }^{14}$ also observed the finding of significantly decreased beta activity in depressed pati- ents, but reported a significant increment in theta activity as well. Pozzi et al. ${ }^{15}$ compared qEEG correlates of AD-depressed patients with those without AD. Non-AD depressed patients showed a significant reduction in delta relative power, as well as a significant reduction in alpha relative power to the right hemisphere. In contrast, depressed AD patients, as compared to non-depressed $A D$ patients, showed significant increments in delta and theta relative power, as well as a significant reduction of alpha relative power, which was restricted to posterior brain regions ${ }^{16,17}$.

In the last three decades, statistical techniques have been used to quantify electrophysiological characteristics associated to a database. Specifically, Neurometrics is the statistical analysis of standardized, neurophysiological measures extracted from the EEG and compared to a normative database ${ }^{18-24}$. Significant deviations from normal Neurometric values are detected in high proportions of patients with psychiatry illness, including developmental disorders and early stages of dementia. Such normative data has helped to differentiate pathologies related to abnormal brain patterns ${ }^{25,26}$. Along this line, here we present qEEG results based on quantitative analysis and statistical assessment of brain electrical features of two different samples: demented and depressive patients. Essentially, the main goal of this experiment was to differentiate patterns of electro-neurophysiological measures, which discriminate depressive from demented patients, and to assess the predictive value of the obtained discriminant equation.

\section{METHOD}

Subjects - The Quantitative EEG (qEEG) recordings of 125 patients from the Alzheimer Day Center (ADC) established at the Institute of Psychiatry (Federal University of Rio de Janeiro, Brazil) were analyzed. Seventy-four (59.2\%) individuals were classified according to DSM-IV criteria (American Psychiatric Association) as dementia (Primary Degenerative Dementia) with depressive symptoms. All patients were diagnosed as Alzheimer type dementia and had been under treatment for at least six months at the time of the evaluation. The treatment included the administration of the following medications: sertraline, fluoxetine, and venlafaxine (depression); and donepezil (Alzheimer). Moreover, severity of cognitive impairment was evaluated by the Mini Mental State Examination ("Folstein Scale"). Fifty one (40.8\%) were diagnosed as having depression (Major Depressive Disorder) associated with mild cognitive impairment. Furthermore, depressed 
participants were diagnosed using the Structured Clinical Interview for DSM-IV Diagnosis, and severity of depression was assessed by the Hamilton Depression Scale. In both groups, the severity of cognitive impairment and of depression varried from mild to moderate (Hamilton = 8-18; Mini-Mental = 13-26). Total mean age was 67.9 years $( \pm 10.5)$, respectively, 72.6 years $( \pm 9.4)$ for demented and 61.0 years $( \pm 8.0)$ for depressed patients. Both groups signed a consent form and the experiment was approved by an Ethics committee (Federal University of Rio de Janeiro - UFRJ).

Data acquisition - Patients and controls were seated in a comfortably sound and light attenuated room, while 20 minutes or more of eyes-closed alert/resting EEG data were collected from the 19 mono-polar electrodes sites. International 10/20 System (referred to linked earlobes) for electrode placement was used with a Braintech-3000 (EMSA-Medical Instruments, Brazil). Eye-movement (EOG) artifact was monitored with a bipolar electrode montage using two 9-mm diameter electrodes attached superior to and on the external canthus of the right eye. Impedances for EEG and EOG electrodes were under $5 \mathrm{~K} \Omega$ and $20 \mathrm{~K} \Omega$, respectively. Visual inspection was employed for detection and elimination of artifacts. Moreover, Independent Component Analysis (ICA) was applied to remove possible sources of artifacts. Amplifier band-pass was $0.5-70 \mathrm{~Hz}$ (3 dB points), with a $60 \mathrm{~Hz}$ notch filter. Data were digitized at $200 \mathrm{~Hz}$ with a 12-bit resolution.

Data analysis - At least two minutes of artifact-free data were extracted from the EEG's total record for quantitative analysis. Power-spectral analysis was performed with Fast Fourier Transform (FFT). For each of the 19 monopolar derivations, absolute and relative (\%) power, mean frequency, inter-hemispheric and intra-hemispheric coherence, and symmetry were computed for the delta $(1.0-3.5 \mathrm{~Hz})$, theta $(4.0-7.5 \mathrm{~Hz})$, alpha $(8.0-12.0 \mathrm{~Hz})$, and beta $(13-25 \mathrm{~Hz})$ frequency bands. Quantitative measures were log-transformed (i.e., $X^{\prime}=\log _{10} X ; X^{\prime}=\log [X /(1.0-X)]$ ) to acquire Gaussianity (i.e., to obtain a normal distribution). Physiological measures very often do not present a normal distribution, which may increase the probability of Type I (false positive) and Type II (false negative) errors. Logtransform alters the distribution of the raw data (i.e., normalizing), without changing the relationship between the scores. This improves the specificity and sensitivity of the quantitative analysis.

The Normative Database from the Brain Research Center (New York University) was used to compare the patients studied with normal controls ${ }^{27}$. This Database (normal individuals) takes into account an aged regression for the qEEG parameters and estimates an overall mean value and standard deviation throughout the whole age range of 6 to 90 years. This procedure is adopted to minimize normative data errors and to reduce the variance.

Discriminant analysis functions - Multiple Discriminant Analysis is one of the most used algorithms for describing major differences among groups, or classifying individuals into groups on the basis of a battery of measurements. The main differences among the populations are brought to light through the use of uncorrelated linear combinations of the primary variables. Considering that the discriminant functions are uncorrelated, they allow a supplementary partitioning of the between association. Application of the discriminant function-variable correlations allows the designation of the discriminant functions, and consequently the standardized index is mandatory to establish which of the variables are unnecessary.

\section{RESULTS}

Descriptive statistic analyses were performed to characterize demented versus depressed patients, in relation to age. T-test analysis (Table 1) showed that there was a significant difference between samples $(t=7.2 ; g l=123 ; p<0.001)$. Results indicated that demented individuals presented a mean age higher than depressed subjects. This fact did not interfere in the overall results, once the EEG data was submitted to an aged regression equation to adjust electroencephalographic parameters. Both groups presented homogeneity of variance ( $F$ ratio var $=1.4, p$ var $=0.2$. .

Initially, 11 qEEG variables, as listed in Table 2, were submitted to a forward stepwise discriminant analysis (SPSS-10) to determine those that best predicted to which subgroup each patient should be allocated (Dementia / Depression). The variables that did not achieve statistical significance level $(p>0.05)$ to enter the discriminant equation were: NMRPA01 (0.74), NMRPBA (0.55), NBACC (0.09), NBACC (0.91), NBACA (0.15), and

Table 1. Descriptive statistic analyses and T-test analysis performed to characterize demented versus depressed patients related to age.

\begin{tabular}{lccccc}
\hline Diagnosis & N & $\begin{array}{c}\text { Mean } \\
\text { Age }\end{array}$ & Minimum & Maximum & $\begin{array}{c}\text { Std } \\
\text { Dev }\end{array}$ \\
\hline Dementia & 74 & 72.6 & 52.2 & 90.3 & \pm 9.4 \\
Depression & 51 & 61.0 & 49.6 & 82.3 & \pm 8.0 \\
Total & 125 & 67.9 & 49.6 & 90.3 & \pm 10.5 \\
\hline
\end{tabular}


Table 2. Quantitative variables submitted to a forwad stepwise discriminant analysis to find out those that best predicted to which subgroup each patient shoud be allocated (dementia/depression). Variables in bold were selected and entered the model.

qEEG Variables

1. Normed Monopolar Relative Power Theta for $\mathrm{Cz}$

2. Normed Monopolar Relative Power Alpha for P3

3. Normed Monopolar Relative Power Alpha for 01

4. Normed Monopolar Relative Power Beta for Anterior

5 Normed Bipolar Relative Power Theta for Head

6. Normed Bipolar Relative Power Total for T3-F7

7. Normed Bipolar Asymmetry Combined for Central

8. Normed Bipolar Asymmetry Combined for Anterior

9. Normed Bipolar Coherence Delta for Fronto-Temporal

10.Normed Bipolar Coherence Delta for Parieto-Occipital

11.Normed Bipolar Coherence Combined for Anterior qEEG variables proposed initially to forward stepwise discriminant analysis.

NBCDPO (0.22). The 5 qEEG variables selected by stepwise forward discriminant analysis are shown in bold (Table 2). These variables allow an effective discrimination between dementia and depression. Lambda value $=0.38(p \leq 0.0001)$ is significant. Lambda values may vary from 0 (perfect discrimination) to 1 (absence of discrimination). On the other hand, tolerance values (variance ratio due to a particular variable) differ from 0 (zero), indicating that there is no significant redundancy in the discrimination power of the 5 selected variables.

All of the 11 qEEG variables that entered the forward stepwise discriminant function analysis presented normal distribution, as well as homogeneity of variance. Normal Distribution and Homogeneity of Variance are basic pre-requisites that must not be violated when applying parametric statistical methods, such as in the case of forward stepwise discriminant function analysis. The 5 qEEG variables that entered the final discriminant equation were: NMRPTC ${ }_{2}$ NBCDFT, NMRPAP3, NBRPTH, and NBRPTT3-F7. It must be stressed that the variable/patient ratio was always bigger than $1 / 10$, in fact it was $1 / 25$. A proportion $\geq 1 / 10$ is necessary for a reliable predictive value of the discriminant function. This pre-requisite was fully respected in this experiment.

For a reliable predictive value of a discriminant equation, it is assumed that the variance / covariance matrices of variables are homogenous across subgroups. Results indicate that the Null Hypothesis of equal variance / covariance matrices should not be rejected ( $p=0.08>0.05)$. It is necessary to mention that the multivariate Box $M$ test for homogeneity of variances / covariances is particularly sensitive to deviations from multivariate normality, and should not be taken into account once the assumption is violated.

Figure 1 shows the standard deviation means for Dementia/Depression from the control group for the 5 qEEG variables analyzed. The deviations

\section{Standard Deviation Means for Clinical Diagnosis (Dementia/Depression)}

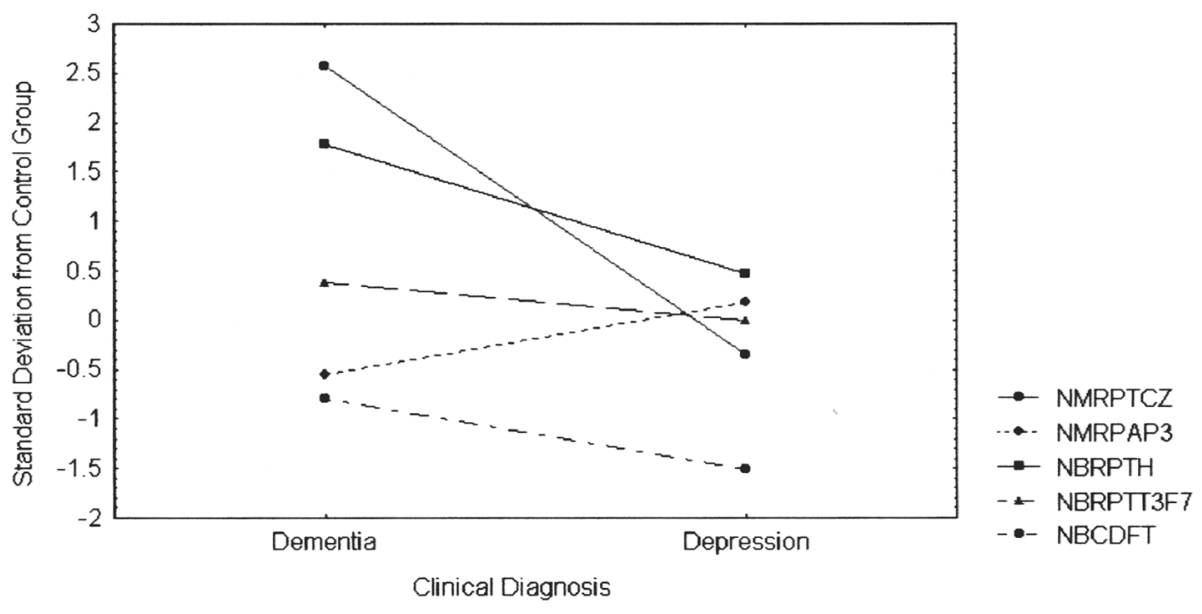

Fig 1. Standard deviation means for Dementia/Depression from the control group for the 5 qEEG variables analyzed. The deviations above the control group occur with variables associated to slow rhythms. 
Table 3. Agreement ratio of correctly classified cases derived from the discriminant function obtained with the 5 qEEG variables in comparison to the Clinical Diagnosis (DSM-IV) for each subgroup (Dementia/Depression).

\begin{tabular}{lcccc}
\hline Group & $\begin{array}{c}\text { Percent } \\
\text { correct }\end{array}$ & $\begin{array}{c}\text { Dementia } \\
(59 \%)\end{array}$ & $\begin{array}{c}\text { Depression } \\
(41 \%)\end{array}$ & Total \\
\hline Dementia & 91.9 & 68 & 6 & 74 \\
Depression & 90.2 & 5 & 46 & 51 \\
Total & 91.2 & 73 & 52 & 125 \\
\hline
\end{tabular}

Classification matrix construction: discrimination function sample data.

above the control group occur with variables associated to slow rhythms: Normed Monopolar Relative Power Theta for Cz (NMRPTCz) and Normed Bipolar Relative Power Theta for Head (NBRPTH), in demented patients. Otherwise, the deviation below the control group occurs with the variable associated to alpha rhythm: Normed Monopolar Relative Power Alpha for P3 (NMRPAP3), in dementia.

The Classification Matrix in Table 3 presents information about the agreement ratio of correctly classified cases derived from the discriminant function obtained with the 5 qEEG variables in comparison to the Clinical Diagnosis (DSM-IV) for each subgroup (Dementia/Depression) (Fig 2).

As pointed out in Table 3, there is a significant agreement degree $(91.9 \%$ for dementia, $90.2 \%$ for depression, and a total of $91.2 \%$ ) between the clinical diagnosis (DSM-IV) and the qEEG diag- nosis based on stepwise forward discriminant function analysis.

The Classification is based on Mahalanobis' distances. For each subgroup, it is possible to determine the location, in a multivariate space, of points that represent the means for all the 5 qEEG variables studied. These points are named Centroids, and for each patient the Mahalanobis' distances are computed from the centroid of each subgroup (Dementia / Depression). A particular case (patient) will belong to the nearest subgroup, that is, where the Mahalanobis' distance is the smallest.

A Receiver Operator Characteristic (ROC) Curve was constructed, using the discriminant scores obtained for each patient (Depression / Dementia), aiming to assess the discrimination power of the qEEG variables. The results for ROC are plotted in Figure 3. As specified in this figure, the area under the curve (0.979) indicates a quite good performance of the combination (discriminant scores) for the 5 qEEG variables in differentiating dementia from depression. At the cut-off point (0.38) suggested by the forward stepwise discriminant function analysis, the sensitivity and specificity for the diagnostic of dementia are $91.9 \%$ and $92.2 \%$, respectively. The positive predictive value and negative predictive value for dementia are $94.4 \%$ and $88.7 \%$, and the global efficiency is $92.0 \%$. Cross-Validation was assessed by the jackknifing method, where each case is classified by the function derived from all cases

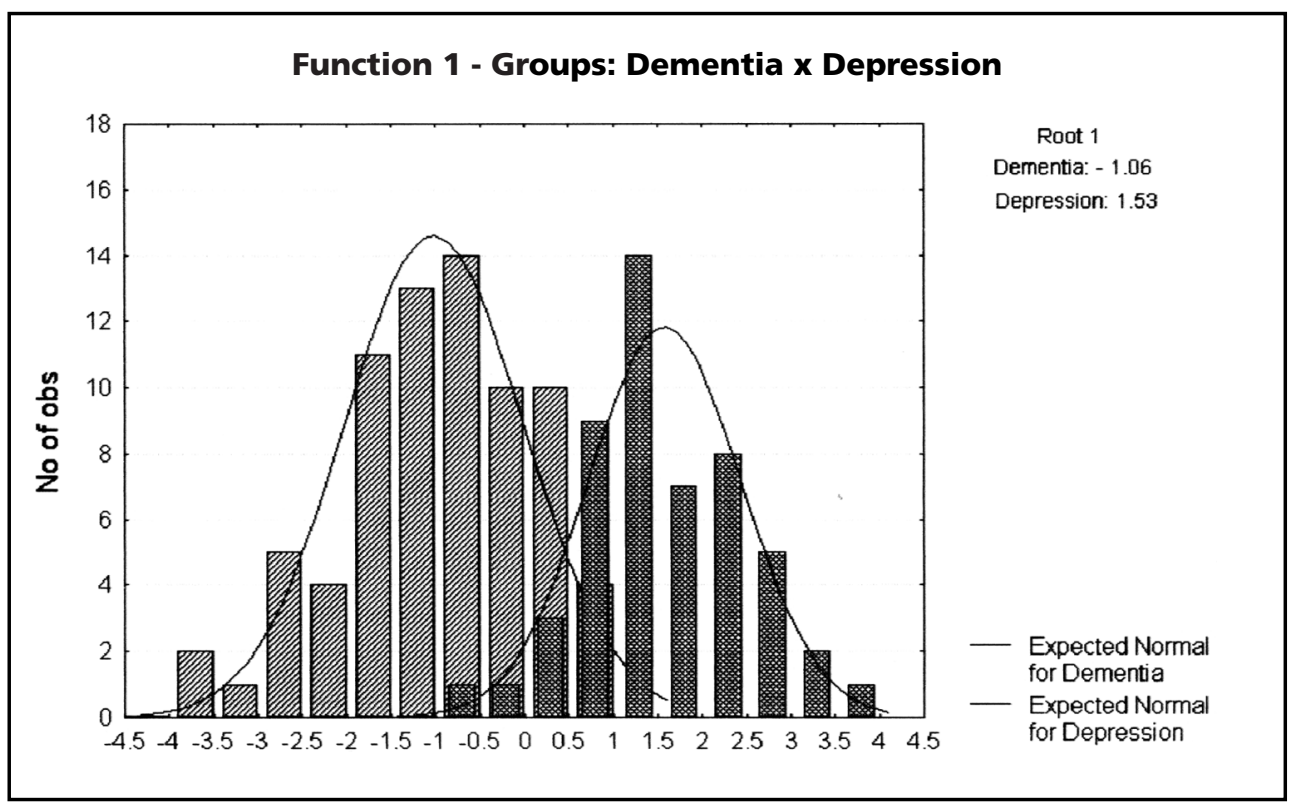

Fig 2. Discriminant function obtained from the 5 qEEG variables previously described. 


\section{Receiver Operator Characteristics (ROC) Curve Discriminant Scores by Clinical Diagnosis (DSM-IV)}

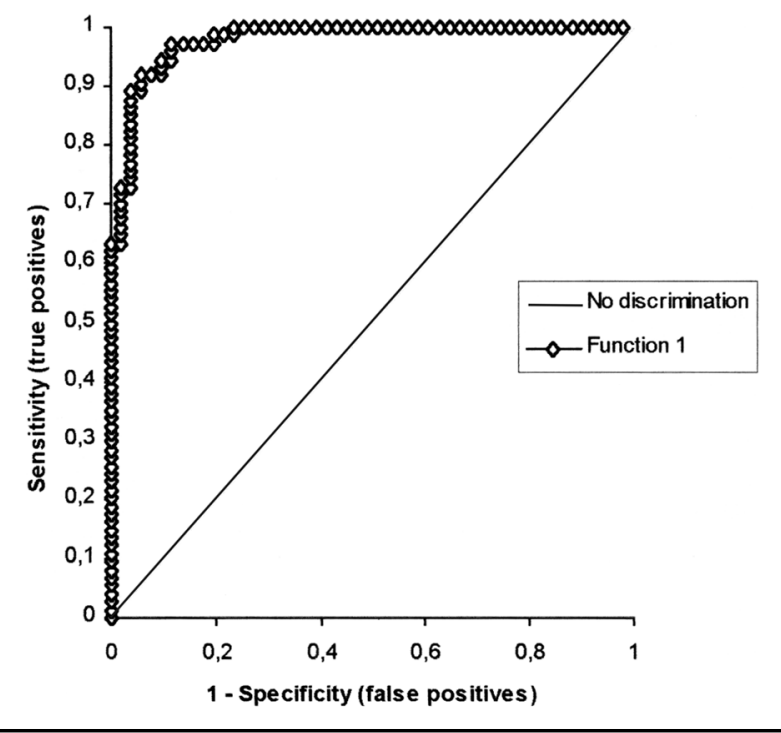

Fig 3. The area under the curve (0.979) indicates a quite good perfomance of the combination (discriminant scores) for the 5 qEEG variables in differentiating dementia from depression.

other than the case itself. The concordance rate between the clinical diagnosis and the 5 qEEG variables diagnosis is still high $(91.9 \%$ for dementia, $88.2 \%$ for depression, and a total of $90.4 \%$ ), indicating that the predictive value of the discriminant equation derived from this study is quite favorable.

\section{DISCUSSION}

This study aimed to identify profiles of qEEG, which may help to differentiate depressive from demented patients. The present experiment contributes to the development of a quantitative tool to uncover psychiatric features related to dementia and depression. Such features are embedded in the shared parameters of both psychiatric disorders. Our results are in agreement with other research groups that use Neurometrics ${ }^{10,19,22,28}$. The ratio of concordance between the clinical diagnosis (DSM-IV) and the qEEG diagnosis based on stepwise forward discriminant function analysis is quite significant ( $91.9 \%$ for dementia, $90.2 \%$ for depression, and a total of $91.2 \%$ ), even for replication $(91.9 \%$ for dementia, $88.2 \%$ for depression, and a total of $90.4 \%$ ), indicating that the predictive value of the discriminant equation derived from this study is favorable.
More specifically, variables associated to slow rhythms present deviations above the control group in demented patients; Normed Monopolar Relative Power Theta for Cz (NMRPTCz) and Normed Bipolar Relative Power Theta for Head (NBRPTH) are increased, when compared to the Neurometrics Normative Database. Otherwise, the deviation below the control group occurred with the variable associated to alpha rhythm, Normed Monopolar Relative Power Alpha for P3 (NMRPAP3). These results are also in concordance with the literature concerned with spectral analyzed EEG in dementia, which consistently shows an increase in absolute and relative slow frequency power, as well as a reduction of the power in higher frequencies and the alpha activity ${ }^{9-13}$. It must be pointed out that there is no conclusive evidence that the drugs that were administred in this study, which are part of the new generation of anti-depressants (Selective Serotonin/Noradrenaline Reuptake Inhibitors - SSRIs and SNaRIs), produce significant alterations in the EEG pattern.

The present results support the hypothesis that qEEG can be used to supplement traditional clinical evaluation in discriminating demented from depressive patients. Although the sample size must be increased, the present findings suggest that the development of a reference database helps to map specific features (Neurometric profiles) for each psychiatric disorder (i.e., dementia $\times$ depression, as in the present situation). Besides, the increment on the number of subjects aids the development of better discriminant equations.

\section{REFERENCES}

1. Berger H. Electroencephalogram of man. Arch Psychiat Nervenkr 1937; 106:577-584.

2. Duffy FH, Iyer VG, Surwillo WW. EEG in clinical diagnosis and its relationship to other neurological tests in clinical electroencephalography and topographic Brain Mapping. Springer-Verlag, 1989;242252.

3. Brenner RP. EEG and dementia. In Niedermeyer E, Lopes da Silva F. Electroencephalography: basic principles, clinical applications and related fields. Baltimore: Williams \& Wilkins, 1993;339-349.

4. Harner RN. EEG evaluation of the patient with dementia. In Benson FD, Blummer D. Psychiatric aspects of neurological diseases. New York: Grune \$ Stratton, 1975;63-82.

5. Pollock VE, Schneider LS. Quantitative, waking EEG research on depression. Biol Psychiatry 1990;27:757-780.

6. Brenner RP, Ulrich RF, Spiker DG. Computerized EEG spectral analysis in elderly normal, demented and depressed subjects. Electroencephalogr Clin Neurophysiol 1986;64:483-492.

7. Lopes da Silva F. EEG analysis: theory and practice. In Niedermeyer E, Lopes da Silva F. Electroencephalography: basic principles, clinical applications and related fields. Baltimore: Williams \& Wilkins, 1993;1097-1123.

8. Piedade RAM. Análise quantitativa da atividade elétrica cerebral. In Bueno JR, Nardi AE. Diagnóstico e tratamento em psiquiatria. Rio de Janeiro: Medsi, 1999;111-125. 
9. Duffy FH, Albert MS, McAnulty G. Brain electrical activity in patients with presenile and senile dementia of the Alzheimer type. Ann Neurol 1984;16:439-448.

10. Prichep L, Mont FG, John ER, Ferris SH. Neurometric electroencephalographic characteristics of dementia. In Reisberg B. Alzheimer's disease: the standard reference. New York: MacMillan 1983;339-348.

11. Coben LA, Danziger WL, Berg L. Frequency analysis of the resting awake EEG in mild senile dementia of the Alzheimer type. Electroencephalogr Clin Neurophysiol 1983;55:372-380.

12. Brenner RP, Reynolds CF, Ulrich RF. Diagnostic efficacy of computerized spectral versus visual EEG analysis in elderly normal, demented and depressed subjects. Electroencephalogr Clin Neurophysiol 1988;69:110-117.

13. Leuchter AF, Spar JE, Walter DO, Weiner H. Electroencephalographic spectra and coherence in the diagnosis of Alzheimer's-type and multiinfarct dementia: a pilot study. Arch Gen Psychiatry 1987;44:993-998.

14. Luthringer R, Minot R, Toussaint M, Dago KT, Soufflet L, Macher JP. Neurophysiological characterization of depressed patients suffering from a major depressive episode using 3D EEG and EPs mapping techniques. Biol Psychiatry 1992;31:73A.

15. Pozzi D, Golimstock A, Petracchi M, Garcia H, Starkstein. Quantified electroencephalographic changes in depressed patients with and without dementia. Biol Psychiatry 1995;38:677-683.

16. Kwa VIH, Weinstein HC, Meyjes EFP, et al. Spectral analysis of the EEG and 99-Tc-HMPAO Spect-scan in Alzheimer's disease. Biol Psychiatry 1993;33:100-107.

17. John ER, Prichep LS, Fridman J, Easton P. Neurometrics: computer-assisted differential diagnosis of brain dysfunctions. Science 1988; 239:162-169.

18. John ER, Prichep LS. Principles of neurometric analysis of EEG and evoked potentials. In Niedermeyer E, Lopes da Silva F. Electroencephalography: basic principles, clinical applications and related fields. Baltimore: Williams \& Wilkins, 1993;989-1003.
19. Prichep LS. Neurometric quantitative EEG measures of depressive disorders. In Takahasi R, Flor-Henry P, Gruzelier J, Niwa S. Cerebra dynamics, laterality, and psychopathology. Amsterdam: Elsevier, 1987;55-69.

20. Thacher R, Walker R, Gerson I, Geisler F. EEG discriminant analysis of mild head trauma. Electroencephalogr Clin Neurophysiol 1989; 73:94-106.

21. Mas F, Prichep L, John ER, Levine R. Neurometric QEEG subtyping of obsessive-compulsive disorder. In Maurer K. Imaging of the brain in psychiatry and related fields. Berlin: Springer Verlag, 1991;277-280.

22. Prichep LS, John ER. QEEG profiles of psychiatry disorders. Brain Topography 1992;4:249-257.

23. Prichep LS, Mas F, Hollander E, et al. Quantitative electroencephalographic subtyping of obsessive-compulsive disorder. Psychiatric Research: Neuroimaging 1993;50:25-32.

24. Piedade RAM, Fiszman A. Diagnóstico diferencial entre demência e depressão utilizando a eletroencefalografia quantitativa (EEGq). J Bras Psiq 1999;48:385-391.

25. Piedade RAM, Fiszman A. Diagnóstico diferencial entre esquizofrenia e depressão maior utilizando a eletroencefalografia quantitativa (EEGq). Psiquiatr Biol 2000;8:109-117.

26. Breslau J, Starr A, Sicotte N, Higa J, Buchsbaum MS. Topographic EEG changes with normal aging and SDAT. Electroencephalogr Clin Neurophysiol 1989;71:281-289.

27. John E, Prichep L, Easton P. Normative data banks and neurometrics: basic concepts, methods and results of norms constructions. In Remond A (ed). Handbook of Electroencephalography and Clinical Neurophysiology, vol. III, Amsterdam: Elsevier, 1987;449-495.

28. Schreiter-Gasser U, Gasser T, Ziegler P. Quantitative EEG analysis in early onset Alzheimer's disease: a controlled study. Electroencephalogr Clin Neurophysiol 1993;86:15-22. 